\title{
Barriers affecting utilization of family planning services among rural Egyptian women
}

E.M. Eltomy, ${ }^{1}$ N.E. Saboula ${ }^{2}$ and A.A. Hussein ${ }^{2}$

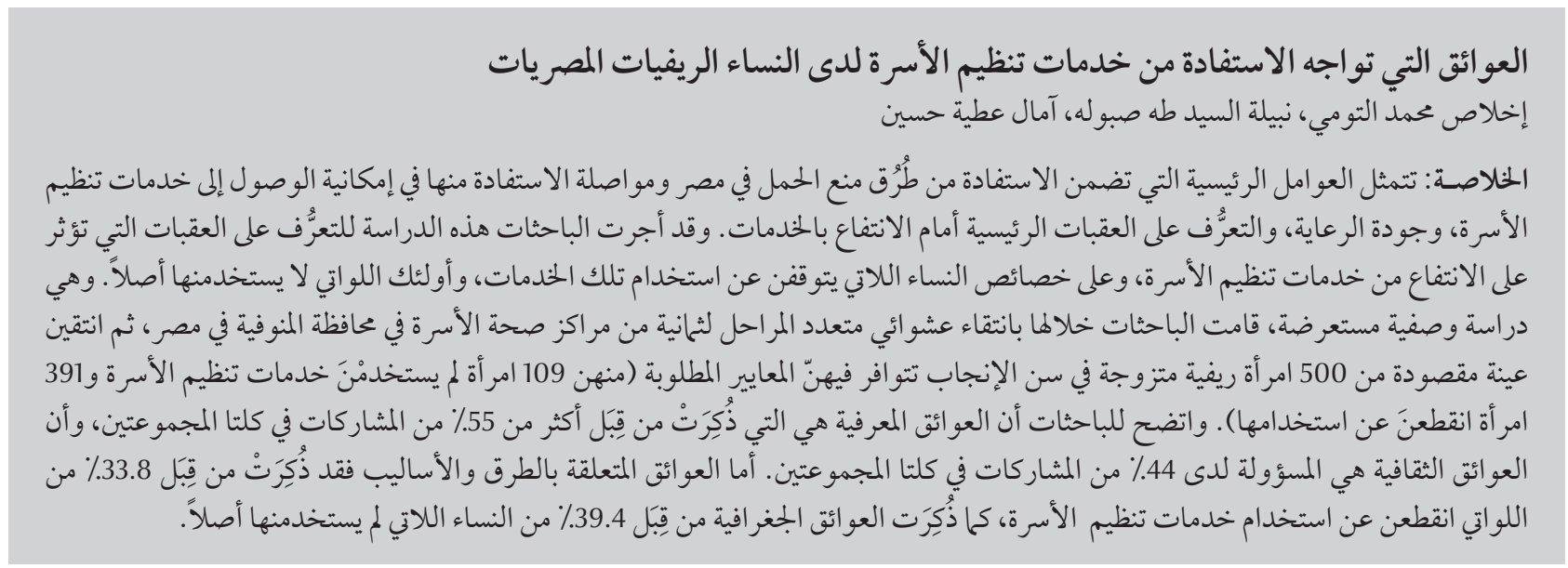

ABSTRACT Access to family planning (FP), quality of care and exploring barriers to utilization of services are key factors in the adoption and continuation of contraception in Egypt. We conducted this study to explore the barriers affecting utilization of FP as well as the characteristics of women who discontinue using FP and nonusers of the FP services. A descriptive cross-sectional research design was used. A multistage random selection of 8 family health centres in Menufia Governorate, Egypt was done. We selected a purposive sample of 500 married, rural women of reproductive age who fulfilled the required criteria (109 non-users, 391 discontinued). Cognitive barriers were cited by more than $55 \%$ of the participants in both groups and cultural barriers by $40 \%$ of both groups. Barriers related to the method were cited by $35.8 \%$ of the women who had discontinued, and demographic barriers by $39.4 \%$ of the non-users.

Obstacles influant sur l'utilisation des services de planification familiale par des femmes égyptiennes en milieu rural

RÉSUMÉ L'accès à la planification familiale, la qualité des soins et l'étude des obstacles à l'utilisation des services sont des facteurs clés pour l'adoption durable de la contraception en Égypte. Nous avons mené une étude pour passer en revue les obstacles influant sur l'utilisation de la planification familiale ainsi que sur les caractéristiques des femmes qui cessent d'avoir recours à ces services ou ne les utilisent pas. Nous avons choisi de mener une étude descriptive transversale. Dans le gouvernorat de Menoufia (Égypte), huit centres de santé familiale ont été sélectionnés par échantillonnage aléatoire à plusieurs degrés. Nous avons sélectionné un échantillon par choix raisonné de 500 femmes mariées en âge de procréer, vivant en milieu rural et répondant aux critères requis (109 non-utilisatrices, 391 anciennes utilisatrices). Dans les deux groupes, des obstacles cognitifs ont été mentionnés par plus de $55 \%$ des participantes et des obstacles culturels par $40 \%$ des participantes. Les obstacles liés à la méthode étaient en cause pour 35,8\% des anciennes utilisatrices tandis que les obstacles démographiques concernaient $39,4 \%$ des non-utilisatrices. 


\section{Introduction}

A woman's ability to space and/or limit her pregnancies has a direct impact on her health and well-being as well as on the outcome of each pregnancy [1]. Family planning (FP) is a major contributing factor towards child survival and reduction in maternal mortality. The relevance of FP in any strategy for safe motherhood and child survival is undeniable [2].

More than 100 million women in the less-developed countries, about 17 $\%$ of all married women, would prefer to avoid pregnancy, but are not using any form of FP. Unmet need for contraception can lead to unintended pregnancies, i.e. either unwanted or mistimed, which poses risks for women, their families and society. In the less-developed countries, about one-fourth of pregnancies are unintended [3].

Global population stabilization is dependent upon success in reducing obstacles to universal availability of quality contraception and FP services. Previous research into the barriers to FP service use has highlighted the importance of looking beyond physical access to examining barriers that arise from psychosocial, administrative, cognitive and cultural factors as well as physical barriers and barriers related to the method itself [4].

In Egypt a baby is born every 23.5 seconds [5]. This means an increase of some 3680 people every day. At this rate, the population is increasing by almost 112200 every month. In 2000 alone, the population rose by more than 1.3 million [5]. In January 2001, 64.6 million people were living in Egypt [5]. The population had risen to 78.7 million in May 2008 [6]. According to surveys from 2007 and 2008, the total fertility rate is 3.1 children/woman, unplanned births reached $17 \%$ and unmet need for family planning is $10 \%[6,7]$.

According to Egyptian MOH statistics [unpublished report. Health Affairs
Province, Family Planning Administration, Menufia Governorate, 2009], fertility has shown some increase in Egypt in the recent years, but contraceptive use remains low. Also, the FP programme has failed to implement many of the recommendations of the 1994 Conference on Population and Development [8], which sought to solve the population problem through reproductive health services and empowerment of women through encouraging youth to contribute proactively to the development programmes [9].

The decision to use or not to use FP services is the product of a number of demographic and service-related barriers. Policy-makers and programme managers can strengthen FP programmes by understanding and using data on unmet need, considering the characteristics of women and couples who have unmet needs, and working to remove obstacles that prevent individuals from choosing and using a FP method [10].

Significant to the study, the rate of normal births in Menufia Governorate increased during the 5 years from 2003 to 2008. Data from 2008 indicated that the utilization rates of FP services are decreasing and the natural increase rates are increasing from 2002 until 2007 [Unpublished report, Health Affairs Province, Family Planning Administration, Menufia Governorate, 2008]. The decrease in the utilization of birth control methods contributes to the rapid increase of population by about 2 million/year [11].

The aim of the study was to explore the various types of reported barriers for both the discontinued and the nonusers women.

\section{Methods}

We used a descriptive, cross-sectional, exploratory study design. The study was conducted using a multistage random selection technique in Tala district, Menufia governorate, Egypt. From a total of 27 units, 8 Family Health Units were randomly selected. These units serve 19 villages, 330579 people. Remote areas were also considered in the study setting.

A survey was made of married women of reproductive age (15-45 years) who were registered on the Family Statistical Register at the selected rural health units as non-users of FP or had previously been users and had discontinued. The register contains names, addresses, jobs, marital status; and woman's status of using or not using a family planning method, health status and telephone number of all family members. Continuation of using or not using FP is not constant, however 1228 women were identified in the registers in the 8 health units at the time of the study. A purposive sample of half of those women was made ( $n$ $=614$ ). The selected women were approached in their homes through the rural community leader and invited to participate in the study. The selection criteria were: women who had stopped using FP methods (discontinued) and women who had never used any FP method. Exclusion criteria were: women who stopped using FP because their husbands were working abroad, women who had had a hysterectomy and women who were pregnant. A total of 560 women agreed to participate. Out of these, 60 refused to participate in the study, leaving a final study sample of 500 .

The sample was divided into 2 groups: Group 1 was 109 women who had never used an FP method (non-users); Group 2 was 391 women who had been users in the past (discontinued).

Participants were interviewed at the Family Health Units. Those women who could not get to the health units for any reason were interviewed at their homes. The women were interviewed by the researchers who had attended a standardized training session at the Faculty of Nursing at Menufia University to ensure the quality and standardization 
of the interviews. Data were collected on 2 days per week over a period of 8 months from September 2008 to April 2009.

\section{Data collection}

A modified version of the Family Planning Evaluation Interviewing Questionnaire (8 items) was used. This was developed by the Ministry of Health and Population and is used at all government clinics and rural units.

The tool comprises 2 forms. The first was used to collect information on the women's characteristics such as age, duration of marriage, age at marriage, education, husband's education reproductive history, and data about FP utilization.

The second form was designed by the researchers from the literature review and was validated by 2 experts in the field of community health nursing and 2 experts of obstetric and gynaecology nursing. It contains a checklist regarding intention to have children in the future, intention to use FP in the future and barriers/reasons for stopping or not using FP services. It has questions on 9 types of barrier:

- cognitive (did not hear or see any advertisement about FP in last 6 months/did not participate in an educational session about FP during last 6 months/think that FP is good behaviour in a woman's life),

- cultural (have bad belief about FP, e.g. loop can penetrate the heart, injection can cause infertility, pills can cause cancer/ child-bearing is more comfortable a at younger age/non traditional methods of FP can harm the woman's health/presence of a male physician prevent women from being investigated/reluctance to discuss sexual behaviour and problems with male physicians/ideal number of children),

- demographic (desire to have children because of low parity/FP should be used only for older women who do not want children/difficulty becoming pregnant/),

- barriers related to the method itself (desire to have the most effective method/have failed in using FP methods and causes of this failure/ method used induced serious sideeffects such as severe pain in chest or abdomen, severe headache, severe depression, severe bleeding),

- reproductive (absence of intercourse/long intervals between intercourse/side-effects such as bleeding, spotting or amenorrhoea),

- psychosocial (someone bans you from using FP, e.g. husband, motherin-law, self),

- physical (engaged in activities throughout the day/distance to clinic is long),

- medical barriers such as requiring women to return more often than necessary for check-ups, requiring spouse's consent as a prerequisite for prescribing contraception, requiring woman to be on her period to start hormonal or IUD methods)

- administrative barriers such as poor quality of service, previous bad experience with the facility, service provider's attitude, lack of privacy during examinations, shortage of stock, etc.

Woman could select any number of barriers. Response was recorded as agree or disagree. Agree scored 1 and represents a barrier: the higher the score the more barriers there are. Disagree scored 0 and represents no barrier. Scoring was adjusted for some specific questions for which disagreement represented a barrier and vice versa; in these cases agree scored 0 and disagree scored 1.

A multiple choice evaluation sheet developed by the Ministry of Health and Population in 2008 was completed only by participants who had had previous contact with an FP clinic but had discontinued using FP. This was used to evaluate participants' satisfaction about the delivered service. It consisted of 2 parts: the first part had 5 statements and was used to assess the characteristics of the waiting area and the waiting time to see a doctor. The second part concerned women's satisfaction with the service rendered to them.

For statistical analysis we used SPSS, version 13. Statistical significance was set at $P<0.05$

\section{Results}

Regarding attitudes to contraceptive use, $75 \%$ of the women who were nonusers said they intended to use FP in the future and $81 \%$ of the women who had discontinued using FP intended to use it in the future (Table 1).

When asked about timing of their future use, only $32.3 \%$ of the non-users said they intended to use FP within 1 year compared with $51.1 \%$ of those who had discontinued using FP (Table 1).

The distribution of each barrier for both groups of women is illustrated in Table 2. The main barriers for the 2 groups were cognitive followed by cultural. Barriers related to the method were reported only by the discontinued women (35.8\%). The third most common response for the non-users was demographic barriers (39.4\%).

Multiple regression analysis showed that cultural, reproductive and demographic barriers were statistically significant factors that affect non-use or discontinuing use of FP (Table 3). Physical and administrative barriers were the least significant predictors.

Table 4 shows the relationship between the reported barriers to using FP services and demographic characteristics of the non-users. We found that 46 of the 77 non-users aged $21-30$ years reported cognitive barriers (59.7\%) and 33 reported cultural barriers (42.8\%). Age at marriage was significantly related to both reproductive and medical barriers $(P<0.05)$. Duration of marriage was significantly related to demographic 
Table 1 Attitude of the 2 groups of participants, non-users $(n=109)$ and women who had discontinued use of family planning (FP) methods $(n=391)$, in regard to future use of contraception

\begin{tabular}{|c|c|c|c|c|c|c|}
\hline \multirow[t]{2}{*}{ Attitude/intention } & \multicolumn{2}{|c|}{$\begin{array}{c}\text { Non-users of FP } \\
(n=109)\end{array}$} & \multicolumn{2}{|c|}{$\begin{array}{l}\text { Discontinued using FP } \\
\qquad(n=391)\end{array}$} & \multirow[t]{2}{*}{$x^{2}$} & \multirow[t]{2}{*}{$P$} \\
\hline & No. & $\%$ & No & $\%$ & & \\
\hline Intend to have children in future & 56 & 51.4 & 140 & 35.8 & \multirow{4}{*}{35.64} & \multirow{4}{*}{0.0001} \\
\hline Intend to use FP in future & 31 & 28.4 & 225 & 57.5 & & \\
\hline Will not use in future & 22 & 20.2 & 26 & 6.7 & & \\
\hline Intended timing for using FP in future & \multicolumn{2}{|c|}{$(n=31)$} & \multicolumn{2}{|c|}{$(n=225)$} & & \\
\hline Within 1 year & 10 & 32.3 & 115 & 51.1 & \multirow{2}{*}{3.16} & \multirow{2}{*}{0.076} \\
\hline More than 1 year & 21 & 67.7 & 110 & 48.9 & & \\
\hline
\end{tabular}

*Significant at $P<0.05$.

and medical barriers $(P<0.05)$. Cognitive barriers were reported by $63.6 \%$ of the 66 women who were married for less than 5 years, and

Table 5 presents the relationship between reported barriers to continuation ofFP services and the demographic characteristics of the women who had discontinued use. There was a significant relationship between age and both cognitive barriers and barriers related to the method. There was also a significant relationship between age at marriage and both physical and cognitive barriers.

\section{Discussion}

According to $\mathrm{MOH}$ statistics, around 8 in 10 married women in Egypt wanted no additional children or wanted to delay the next birth for at least 2 years, yet a sizeable proportion did not use contraception [12]. The gap between stated preference and actual behaviour is a measure of what demographers label "unmet need". Also, more than half the women with unmet need indicated that they intended to use FP but were unable to do so [13].

It has been proposed that the proportion of those who intend to use FP in the future is a better measure of demand for contraception than unmet need itself [unpublished report, Health Affairs Province, Family Planning Administration, Menufia Governorate, 2009]. In this study, the majority of the nonusers of FP and the women who had discontinued use said they intended to have children and intended to use FP methods in the future. These findings presented a discrepancy between what the women want and what they really do. This could be because many
Egyptian women want to have greater control over reproductive decisions, but they lack the knowledge and need proper counselling.

It has been reported that behaviour change goes through the following stages: knowledge, approval, intention, use, and advocacy $[14,15]$. Such findings could explain that women's intention reflects their ability to respond to health education sessions about contraception according to whether their needs are met

\section{Barriers to use and discontinuation of contraception}

The present study explored the various types of reported barriers for both the discontinued group and the non-users. Cognitive, cultural and demographic barriers were the main barriers that lead to not using/discontinuation of FP

Table 2 Reported barriers for discontinuation/not using family planning (FP) services among non-users of FP methods $(n=$ $109)$ and women who had discontinued using FP $(n=391)$

\begin{tabular}{lcccc} 
Barrier & \multicolumn{2}{c}{ Non-users of FP } & \multicolumn{2}{c}{ Discontinued using FP } \\
& No. & $\%$ & No. & 55.5 \\
Cognitive & 61 & 56.0 & 216 & 41.7 \\
Cultural & 44 & 40.4 & 163 & 35.8 \\
Related to method itself & 0.0 & 0.0 & 140 & 33.2 \\
Reproductive & 4 & 3.7 & 130 & 26.3 \\
Demographic & 43 & 39.4 & 103 & 20.5 \\
Medical & 10 & 9.2 & 80 & 19.9 \\
Psychosocial & 22 & 20.2 & 78 & 14.3 \\
Physical & 2 & 1.8 & 56 & 40 \\
Administrative & 17 & 15.6 & 40.2 \\
\hline
\end{tabular}




\begin{tabular}{|c|c|c|c|c|c|}
\hline Barrier & $B$ & SE & $P$ & $\operatorname{Exp}(B)$ & 95\% confidence interval for $\operatorname{Exp}(B)$ \\
\hline Reproductive & 2.535 & 0.285 & 0.0001 & 0.079 & $0.045-0.139$ \\
\hline Demographic & 2.372 & 0.774 & 0.002 & 0.398 & $0.227-0.699$ \\
\hline Cultural & 0.981 & 0.264 & 0.0001 & 2.667 & $1.589-4.476$ \\
\hline Psychosocial & 0.523 & 0.325 & 0.107 & 0.593 & $0.314-1.120$ \\
\hline Related to method itself & 0.483 & 0.261 & 0.065 & 0.617 & $0.370-1.030$ \\
\hline Medical & 0.102 & 0.320 & 0.749 & 0.903 & $0.482-1.692$ \\
\hline Administrative & 0.039 & 0.416 & 0.925 & 0.961 & $0.426-2.172$ \\
\hline Cognitive & 0.035 & 0.256 & 0.892 & 0.966 & $0.584-1.596$ \\
\hline Physical & 0.024 & 0.371 & 0.949 & 0.977 & $0.472-2.023$ \\
\hline
\end{tabular}

$B=$ logistic regression coefficient $; S E=$ standard error of $B ; \operatorname{Exp}(B)=$ estimated odds ratio.

methods followed by barriers related to the method itself and reproductive barriers. The administrative and physical barriers were the least reported ones. This contradicts findings from studies in Nepal and in Jordan, where the researchers related the hesitation to seek out FP services to administrative barriers, which included problems in the health-care delivery system and perceptions of health-care providers, especially their FP counselling skills $[16,17]$. In addition, a study in Pakistan found that half of all urban poor women identified psychosocial reasons as the primary barrier to using family planning services. Administrative barriers were the second most commonly reported barrier, with few women reporting cognitive and physical barriers to FP service use [18]. This could be attributed to subjective perceptions about the barriers and varies from one person to another according to cultural and personal characteristics and the quality of service itself.

The majority of women in both groups in our study thought that FP was good behaviour for a woman's life. However, about half had not heard or seen any advertisement about $\mathrm{FP}$ in the previous 6 months. This reported lack of awareness about contraceptive methods may be a reason for not using contraception among our participants. This is supported by a survey in SubSaharan Africa which indicated lack of media exposure as a prominent reason, cited by most of the women reviewed in the survey [19].

A large proportion of the 2 groups of women in our study said they would refuse to discuss sexual behaviour and problems with a male physician. This means that most Egyptian women preferred a female physician. This situation is not unique to Egypt, it is found also in Jordan [17].

Concerning barriers related to the method itself, more than half of the women who had discontinued using contraception had a desire to have a more effective method. In Indonesia, however, only $8 \%$ of discontinued women related it to the method [20]. This could be due to past experience of failure of the method or the presence of side-effects. This is supported by Aktun et al. who reported that among women using contraception, the majority of unintended pregnancies occurred as a result of inconsistent or incorrect use of the method [21].

Reproductive barriers were reported by almost one-third of the discontinued women but only $3 \%$ of the non-users. This is mainly subjective and depends on previous experience with FP methods.

Around two-thirds of the women in both groups reported that no-one prevented them from using FP. This means that the women felt powerful enough to make their own decisions and have the autonomy to decide for themselves. This was confirmed in another study in Egypt in which only $1 \%$ of discontinuation of the last contraceptive method was related to the husband's disapproval [22]. In contrast, a study carried out in Pakistan reported that psychosocial barriers, which included husband's opposition and religious opposition, accounted for half of the reported barriers to FP service use [18].

Regarding medical barriers, about one-third of the non-users and more than three-quarters of the discontinued women had been told to come back at a later date while they were menstruating. Our findings are supported by evidence from Ghana, Kenya, Cameroon, Jamaica, and Senegal indicating that nonmenstruating women are commonly told they must return when they are menstruating in order to be given a hormonal contraceptive method or to have an intra-uterine device (IUD) inserted [23]. One rationale offered to justify these requirements is that it is cheap and there is no need to do pregnancy tests. A second rationale is that hormonal methods reduce menstrual disturbances when initiated during menstruation, and the IUD is easier to insert at this time. However, this is irrelevant for many women, and inserting IUDs in non-menstruating women offers other benefits, including better diagnosis of 


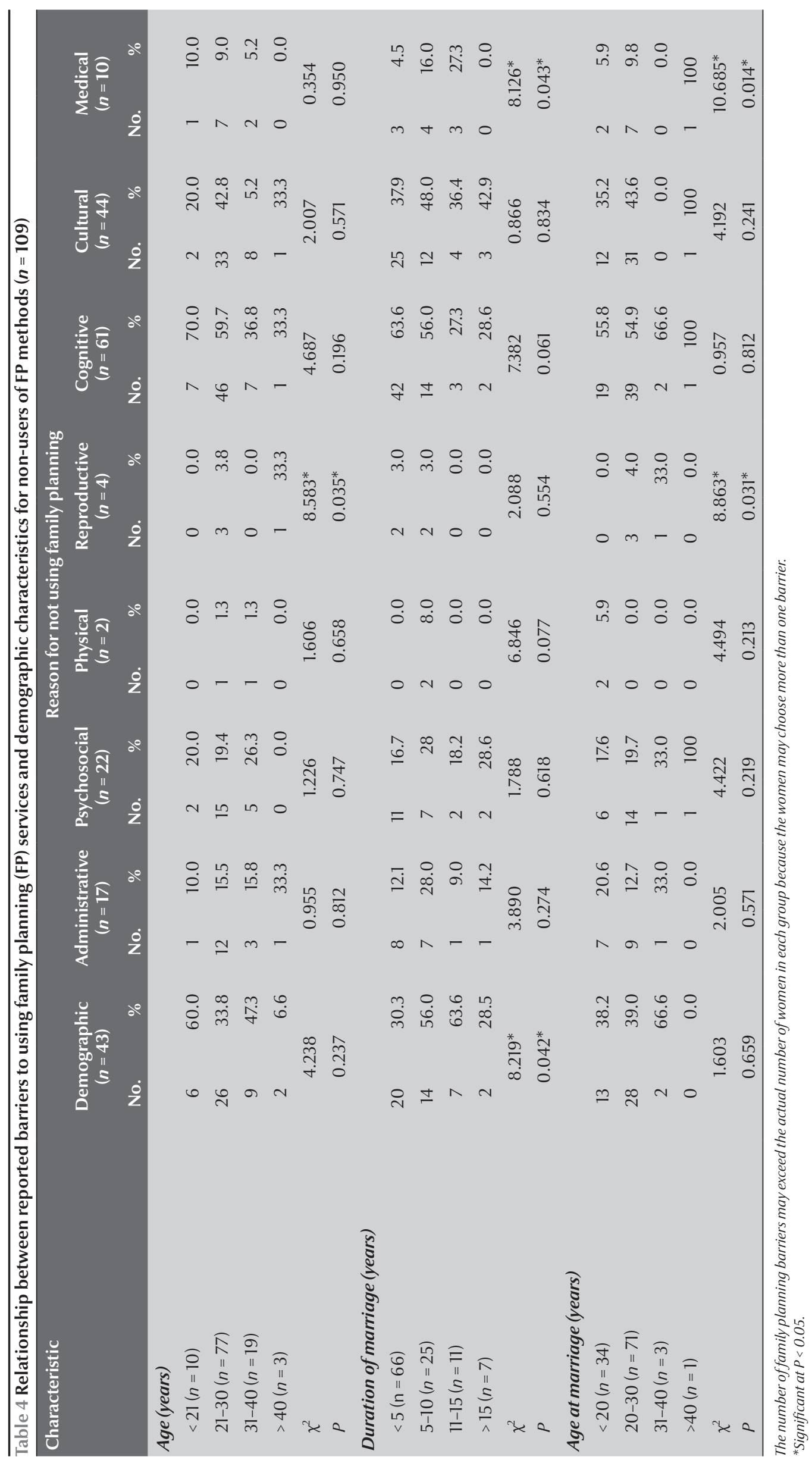




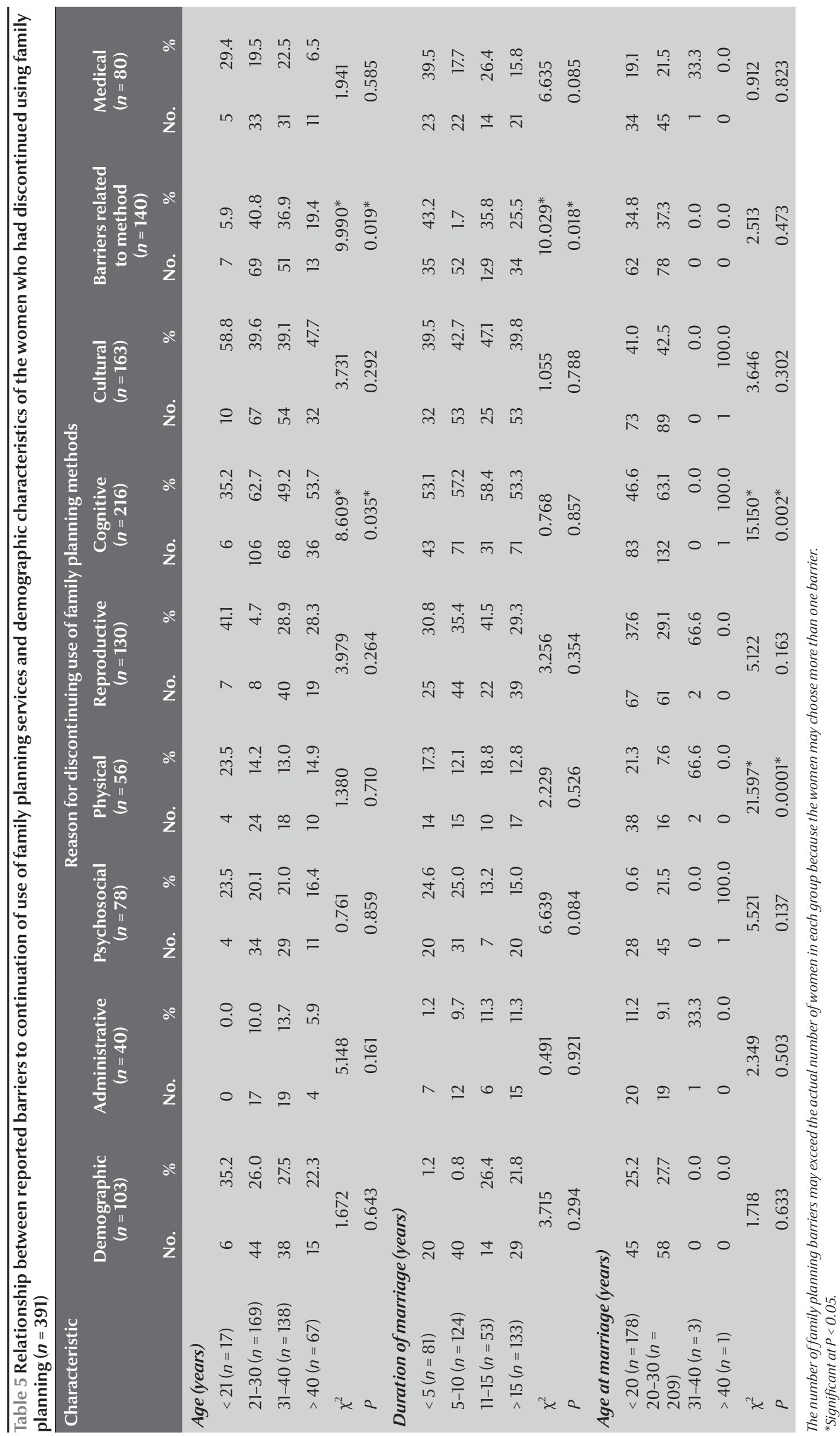


sexually transmitted infections and lower rates of infections and expulsion. The menstrual requirements pose a serious, but under-recognized, barrier to FP.

As for administrative barriers, about one fifth of our participants reported a fear of using the service due to reports of bad experiences by others. This is supported by the findings of 2 other studies where lack of acceptance of FP services was due to unsuitable regulations in the facility $[24,25]$. Administrative barriers could lead to dissatisfaction with the service and reluctance to use it and discontinuation.

\section{Predictors for the future use of family planning services}

We found that cultural barriers were the most significant barriers to future use of contraception, followed by reproductive and demographic barriers. Physical and administrative barriers were the least mentioned. This result is supported by Blank, Curtis and Croft who reported that many people discontinue use even though they do not want to get pregnant and thus expose themselves to the risk of unintended pregnancy due to cultural barriers, barriers related to the method and reproductive barriers [26]. Likewise, in a Pakistani study the most common reasons that women discontinued using contraception, other than desire for pregnancy, were becoming pregnant while using a contraceptive and side-effects or fear of side-effects
[18]. A survey in Asia and Latin America revealed that reproductive barriers were the second most frequently cited reason that fell under the rubric of health concerns, which weighed heavily in these regions [27].

\section{Association between demographic characteristics \& utilization of family planning among discontinued women}

There was a significant relationship between current age, age at marriage, woman's education and husband's education, and both cognitive barriers and barriers related to the method. Similarly, the education status of both the woman and her husband displayed significant positive relationships with a woman's propensity of utilizing FP services in a study in Pakistan [18].

\section{Relationship between reported barriers to using $\mathrm{FP}$ services and demographic characteristics of non-users}

Age was significantly related to reproductive barriers and three-quarters of the non-users were 21-30 years old. Duration of marriage was significantly related to demographic barriers. These findings are reasonable since they relate to the desire to start a family early in the marriage and they are young and less experienced in using FP methods. This finding emphasizes the lack of essential knowledge about FP and these women need specific attention and more information to promote their safety and to avoid unintended pregnancy. This result is supported by other researchers [28] who emphasized that this age group lacks reassurance about what methods promote overall safety and reduce risks. Hassanein reported that $39 \%$ of women in his study were married at age 20-24 years and never used FP services [29]. Women who indicated that they are not using contraception because they do not know about contraceptive methods, could be unfamiliar with specific methods of contraception or could lack an awareness of the concept of family planning or fertility control [30].

\section{Acknowledgements}

We would like to express our gratitude to the Manager of Family Planning of the Health Affairs Province, the Manager of the Medical Facility of Management and the Manager of Family Planning at the Medical Facility of Management, Tala District. We also wish to thank the nurses and women who helped through data collection.

This paper is derived from the MSc thesis of E.M. Eltomy, while studying at Menufia University under the supervision of Dr N. Saboula and Dr A. Hussien in the Department of Community Health Nursing.

Competing interests: None declared.

\section{References}

1. Andrew J. Maryland family planning and reproductive health program. Maryland, Center for Maternal and Child Health, 2005.

2. Littleton-Gibbs LY, Engebretson JC. Maternal, neonatal and women's health nursing, 4th ed. New York, Cengage Learning, 2004:310-313.

3. Ashford L. Unmet need for family planning: Recent trends and their implications for programs. Washington DC, Population Reference Bureau, 2003 (www.prb.org/pdf/UnmetNeedFamPlan-Eng.pdf, accessed 21 November 2012).

4. Elzanaty K, Way A. Egypt Demographic and Health Survey. Cairo, Egypt, Ministry of Health and Population, National Population Council, 2005.

5. Demographic indicators. Cairo, Central Agency for Public Mobilization and Statistics (CAPMAS), 2006.
6. Demographic and Health Survey. The discontinuation rates during the first year of Family Planning use. Cairo, Ministry of Health and Population, Family Planning Sector, 2008.

7. 2007 population census. Cairo, National Population Council, 2007.

8. Programme of Action. Report of the International Conference of Population and Development, Cairo, Egypt, 5-13 September 1994. Cairo, UN Department of Public Information and UNFPA, 1994 (A/CONF.171/13/Rev.1) (available at: http://www. unfpa.org/public/cache/offonce/home/publications/pid /1973; jsessionid=ADFD819B793778ADFE114780886361CF. jahia01, accessed 20 December 2012).

9. El-Zanaty F, Way A. Egypt Demographic and Health Survey 2008. Cairo, Ministry of Health, El-Zanaty and Associates, Macro International, 2009. 
10. Bertrand JT et al. Access, quality of care and medical barriers in family planning programs. International Family Planning Perspectives, 1995, 21(2):64-69.

11. Elzanaty K, Way A. Egypt demographic and health survey 2005. Cairo, Egypt, Ministry of Health and Population, National Population Council, 2005.

12. El-Zanaty F et al. Egypt Demographic and Health Survey 1995. Calverton, Maryland, National Population Council, Ministry of Health and Population (Arab Republic of Egypt) and Macro International Inc, 1996.

13. El-Zanaty F, Way A. Egypt Demographic and Health Survey 2008. Cairo, Egypt: Ministry of Health, El-Zanaty and Associates, Macro International, 2009.

14. Mansour E, Abdel Fatah F. Profile of women with an unmet need for family planning from a child survival perspective. In: El-Zanaty F, Way A, eds. Perspectives on the population and health situation in Egypt. Cairo, National Population Council and Demographic and Health Surveys, Macro International, 1998.

15. Sedgh G et al. Women with an unmet need for contraception in developing countries and their reasons for not using a method. New York, Guttmacher Institute, 2007 (Occasional Report No. 37).

16. Storey JD, Boulay M. Improving family planning use and quality of services in Nepal through the entertainment-education strategy. Baltimore, Maryland, Johns Hopkins School of Public Health, Population Communication Services, 2000 (Field Report No. 12).

17. Shawqi F, Hasna M.Utilization of family planning services in the Governorate of Zarqa. Journal of Transcultural Nursing, 2006, 17(4):365.

18. Stephenson RB, Hennink M. Barriers to family planning service use among the urban poor in Pakistan. Asia-Pacific Population Journal, 2004, 19(2):5-26.

19. Kirk D, Pillet B. Fertility levels, trends, and differentials in SubSaharan Africa in the 1980s and 1990s. Studies in Family Planning, 1998, 29(1):1-22.

20. Magadi M, Diamond I, Rodrigues RN. The determinants of delivery care in Kenya. Social Biology, 2000, 47(3-4):164-188.
21. Aktun H et al. Depo-Provera: use of a long-acting progestin injectable contraceptive in Turkish women. Contraception, 2005, 72(1):24-27.

22. Tolley E et al. The impact of menstrual side-effects on contraceptive discontinuation: Findings from a longitudinal study in Cairo, Egypt. International Family Planning Perspectives, 2005, 31(1):15-23. s/journals/3101505.pdf.

23. Stanback J et al. Menstruation requirements: a significant barrier to contraceptive access in developing countries. Studies in Family Planning, 1997, 28(3):245-250.

24. Curtis S, Neitzel K. Contraceptive knowledge, use, and sources. Calverton, Maryland, Macro International, 1996 (Demographic and Health Surveys Comparative Studies, No. 19).

25. Haddad $\mathrm{S}$ et al. What does quality mean to lay people? Community perceptions of primary health care services in Guinea. Social Science \& Medicine, 1998, 47(3):381-394.

26. Blank A, Curtis S, Croft T. Does contraceptive discontinuation matter? Quality of care and fertility consequences. Chapel Hill, North Carolina, Carolina Population Center, University of North Carolina. 1999 (http://www.cpc.unc.edu/measure/ publications/wp-99-14, accessed 22 November 2012).

27. AbouZahr C, Boerma T. Health information systems: the foundations of public health. Bulletin of the World Health Organization, 2005, 83(8): 578-583.

28. Ali M, Cleland J. Determinants of contraceptive discontinuation in six developing countries. Journal of Biosocial Science 1999, 31(3):343-360.

29. Hassanein MK. Indicators and patterns of reproductive health in the Muslim world. In: Serour GI, Hassanein MK, ed. Proceedings of the International Conference on Population and Reproductive Health in the Muslim World, February 21-24, 1998. Cairo, Al-Azhar University, International Islamic Center for Population Studies and Research, 1998:311-324.

30. Medical eligibility criteria for contraceptive use, department of reproductive health and research. Geneva, World Health Organization, 2004. 